\title{
In Vitro Sorption Study of Some Organochlorine Pesticides on Polyethylene Terephthalate Microplastics
}

\author{
ROXANA-ELENA SCUTARIU ${ }^{1,2 *}$, DIANA PUIU ${ }^{1}$, GHEORGHE NECHIFOR ${ }^{2}$, MARCELA NICULESCU ${ }^{1}$, \\ LUOANA FLORENTINA PASCU ${ }^{1}$, TOMA GALAON ${ }^{1}$ \\ ${ }^{1}$ National Research and Development Institute for Industrial Ecology-ECOIND, 71-73 Drumul Podu Dambovitei, 060652 , \\ 060652, Bucharest, Romania \\ ${ }^{2}$ University Politehnica Bucharest, Faculty of Applied Chemistry and Materials Science, 1-7 Polizu Str., 011061, \\ Bucharest, Romania
}

The main objective of this study was to investigate the adsorption processes occurring on the surface of microplastic particles using an important class of organic pollutants (organochlorine pesticides). The adsorption study of some organochlorinated compounds has shown that these compounds, being in contact with microplastic particles, can be significantly adsorbed (up to 50\% of the added amount controlled in the in vitro study depending on hydrophobicity and water solubility) on their surface and can be transported in natural waters. Contaminated particles may be ingested by aquatic organisms and may bioaccumulate there in causing damage to the entire trophic chain.

Keywords: adsorption, microplastics, organochlorine pesticides, polyethylene terephthalate

Microplastics are those small plastic particles that today are ubiquitous in the environment. Their presence has become a major problem especially for the marine ecosystem. According to literature data, microplastics are defined as plastic particles smaller than $5 \mathrm{~mm}$, their size ranging from $333 \mu \mathrm{m}$ to $5 \mathrm{~mm}$ [1]. Some research studies classified plastic wastes present in the environment in three categories: macroplastic $(<20 \mathrm{~mm})$, mesoplastic $(2-20 \mathrm{~mm})$ and microplastic $(<2 \mathrm{~mm})$ [2]. Other researchers have defined microplastics as those particles hardly visible, with a diameter of $\sim 0.06-0.5 \mathrm{~mm}$ [3].

On the other hand, microplastics have been classified in primary microplastics used in facial-cleansers and cosmetics, air-blasting media and medicine industry and secondary plastics derived from the breakdown of larger plastic debris [4].

The process of fragmentation and decomposition of plastic wastes is responsible for increasing the quantity of microparticles identified in the aquatic environment [5, 6]. Plastic wastes from land-based sources accounts for $60-80 \%$ of marine litter and for $90 \%$ of wastes floating on seas and oceans [7, 8]. Other sources of microplastic pollution are the natural calamities such as floods or hurricanes that accelerate the transport of terrestrial waste in the marine environment; tourism, commercial and recreational fishing, vessels, aquaculture, oil platforms that pose a high risk to both flora and fauna; ship building, plastic industry, laundry and also cosmetics [9].

The most used plastics nowadays are polypropylene (PP), polystyrene (PS), polyethylene terephthalate (PET), polyurethane (PUR), polycarbonate (PC), and polytetrafluoroethylene (PTFE - Teflon) coatings, low-density polyethylene (LDPE), high-density polyethylene (HDPE), polyvinyl chloride (PVC) [10-12].

Marine plastic pellets have different surface structures and, therefore, different affinities to pollutants [13]. Many plastics can adsorb a wide range of compounds known as persistent, bioaccumulative and toxic substances (PBT) including phthalates, polychlorinated biphenyls (PCBs), polycyclic aromatic hydrocarbons (PAHs), nonylphenol (NP), organochlorine pesticides (OPCs) such as dichlorodiphenyltrichloroethane (DDT) or hexachlorocyclohexanes (HCHs), polybrominated diphenyl ethers (PBDEs), alkylphenols, bisphenol A (BPA), parabens, estrogenic steroids, and metals (cadmium, aluminum, zinc) at concentrations from $\mathrm{ng} / \mathrm{g}$ to $\mu \mathrm{g} / \mathrm{g}[10,14-17]$. Some pharmaceuticals such as antibiotics, antidepressants and beta-blockers present in water may be sorbed onto microplastics $[18,19]$.

These organic contaminants are persistent in the aquatic environment and microplastics serves as a vector for them. Adsorption is an essential process governing the distribution, persistence and ecological impact of hydrophobic anthropogenic contaminants in terrestrial and aquatic systems. Once in water, these hydrophobic contaminants are sorbed to the plastic pellets at concentrations of up to $10^{6}$ because of the low polarity (hydrophobic nature) higher than in seawater $[13,20]$.

*email:roxgrigoras@gmail.com 
The physicochemical properties of microplastics such as specific surface area, degree of crystallinity, shape, pore size distribution may dominate their organochlorine pesticides adsorption capacities from the surrounding aquatic environment $[10,21]$.

Microplastics isolated from environmental samples are identified and quantified using several techniques: infrared spectroscopy (IR) one of the most common techniques available for the chemical identification of microplastics, attenuated total reflectance (ATR), $\mu$ Raman spectroscopy, micro Fourier transform infrared ( $\mu$ FT-IR) and the near infrared spectroscopy (NIR) analysis technique in combination with chemometry. Another used technique is pyrolysis-gas chromatography-mass spectrometry (Pyr-GC/MS), a technique that can simultaneously analyze both the type of polymer and the organic additives of microplastics. After extraction from the environmental matrices, the plastic particles are thermally reduced before the GC-MS analysis [22-24].

Due to to their small size, persistence and high occurrence, microplastics can be ingested directly or indirectly by living organisms more quickly than particles with larger diameter and leading to harmful physical effects [25, 26]. Finally, microplastics can interact with water and wastewater treatment process (WWTP) and it could affect the performance of the treatment process [12]. Due to fragmentation of microplastics into nanoplastics in WWTP the physical-chemical properties of these particles can be change, and obviously could appear interactions between nanoplastics and pollutants present in natural waters [24].

The aim of this study was to examine the sorption processes of organochlorine pesticides (OCPs) on microplastics in natural waters. In the present work, the following OCPs: $\alpha, \beta, \gamma, \delta$-HCH isomers, heptachlor, heptachlor epoxide, aldrin, dieldrin, endrin, endrin aldehyde, endosulfan I (alpha), endosulfan II (beta), endosulfan sulfate, dichlorodiphenyltrichloroethane (DDT), dichlorodiphenyldichloroethylene (DDE), dichlorodiphenyldichloroethane (DDD) were selected as the hydrophobic sorbates. All pollutants analyzed are established in the Persistent Organic Pollutants in Stockholm Convention (May 2001) [27]. As sorbents polyethylene terephthalate microplastics were selected. The organochlorine pesticides and PET microplastics were chosen due to their wide-spread presence in aquatic environments. In-vitro experiments were conducted to study the sorption behaviors of organochlorine pesticides by PET microplastics.

Physical-chemical characteristics of investigated pollutants including molecular formula, chemical structure, log $\mathrm{K}_{\mathrm{ow}}$ values, boiling point, molecular weight are presented in Table 1.

Table 1

PHYSICAL-CHEMICAL CARACTERISTICS OF ORGANOCHLORINE PESTICIDES

\begin{tabular}{|c|c|c|c|c|c|}
\hline Compounds & $\begin{array}{c}\text { Molecular } \\
\text { formula }\end{array}$ & Chemical structure & $\log \mathrm{K}_{\mathrm{ow}}$ & Boiling point & $\begin{array}{c}\text { Molecular } \\
\text { weight, } \mathrm{g} / \mathrm{mol}\end{array}$ \\
\hline$\alpha-\mathrm{HCH}$ & $\mathrm{C}_{6} \mathrm{H}_{6} \mathrm{Cl}_{6}$ & & 3.79 & $288^{\circ} \mathrm{C}$ & 290.8 \\
\hline$\beta-\mathrm{HCH}$ & $\mathrm{C}_{6} \mathrm{H}_{6} \mathrm{Cl}_{6}$ & & 3.88 & $60^{\circ} \mathrm{C}$ at $0.5 \mathrm{mmHz}$ & 290.8 \\
\hline$\gamma-\mathrm{HCH}$ & $\mathrm{C}_{6} \mathrm{H}_{6} \mathrm{Cl}_{6}$ & & 3.72 & $323^{\circ} \mathrm{C}$ & 290.8 \\
\hline$\delta-\mathrm{HCH}$ & $\mathrm{C}_{6} \mathrm{H}_{6} \mathrm{Cl}_{6}$ & & 4.17 & $\begin{array}{c}60^{\circ} \mathrm{C} \text { at } 0.36 \\
\mathrm{mmHg}\end{array}$ & 290.8 \\
\hline 4,4-DDT & $\mathrm{C}_{14} \mathrm{H}_{9} \mathrm{Cl}_{5}$ & & 6.36 & $260^{\circ} \mathrm{C}$ & 354.5 \\
\hline 4,4-DDD & $\mathrm{C}_{14} \mathrm{H}_{10} \mathrm{Cl}_{4}$ & & 5.70 & $193^{\circ} \mathrm{C}$ & 320.0 \\
\hline 4,4-DDE & $\mathrm{C}_{14} \mathrm{H}_{8} \mathrm{Cl}_{4}$ & & 5.50 & $88-90^{\circ} \mathrm{C}$ & 318.0 \\
\hline Dieldrin & $\mathrm{C}_{12} \mathrm{H}_{8} \mathrm{O}$ & & $5.38-7.67$ & $385^{\circ} \mathrm{C}$ & 380.9 \\
\hline
\end{tabular}




\begin{tabular}{|c|c|c|c|c|c|}
\hline Aldrin & $\mathrm{C}_{12} \mathrm{H}_{8} \mathrm{Cl} 9$ & $385^{\circ} \mathrm{C}$ & 364.9 \\
\hline Heptachlor & $\mathrm{C}_{10} \mathrm{H}_{5} \mathrm{Cl}_{7}$ & $5.68-7.4$ & $145^{\circ} \mathrm{C}$ & 373.3 \\
\hline $\begin{array}{c}\text { Heptachlor } \\
\text { epoxide }\end{array}$ & $\mathrm{C}_{10} \mathrm{H}_{5} \mathrm{Cl}_{7} \mathrm{O}$ & \\
\hline Endrin & $\mathrm{C}_{12} \mathrm{H}_{8} \mathrm{Cl}_{6} \mathrm{O}$ & & 5.44 & $164^{\circ} \mathrm{C}$ & 389.3 \\
\hline Endosulfan & $\mathrm{C}_{9} \mathrm{H}_{6} \mathrm{Cl}_{6} \mathrm{O}_{3} \mathrm{~S}$ & &
\end{tabular}

\section{Experimental part}

\section{Reagents and chemicals}

A mixed stock solution of $1000 \mathrm{mg} / \mathrm{L}$ of each compound presented in Table 1 was obtained from Dr. Ehrenstorfer (LGC Labor GmbH, Augsburg, Germany). Five calibration solutions were prepared in hexan solvent over the concentration range 2.5-200 $\mu \mathrm{g} / \mathrm{L}$ by diluting the stock solution. Pentachloronitrobenzene (PCNB) was used as internal standard at $2 \mathrm{mg} / \mathrm{L}$ concentration in each sample. Hexane $99 \%$ and Whatman quantitative filter paper were acquired from Merck (Germany) and the anhidrous sodium sulfate was purchased from Chimreactiv (Romania). Polyethylene terephthalate (PET $<5 \mathrm{~mm}$ ) microplastics samples used in the study were prepared in the laboratory from an unused common plastic bottle, using a cutter to obtain sizes between 0.5-5 $\mathrm{mm}$.

\section{$G C-\mu E C D$ instrumentation and conditions}

The chromatographic determination of organochlorine pesticides was performed an Agilent 7890A gas chromatograph with micro electron capture detector $(\mu \mathrm{ECD})$. Analytes were separated with an Agilent HP-5MS type fused-silica capillary column, of (60 m, $0.25 \mathrm{~mm}$ I.D., $0.25 \mu \mathrm{m}$ f.d.). A sample extract volume of $1 \mu \mathrm{L}$ was injected at $280^{\circ} \mathrm{C}$ degrees in split mode (5:1), and carried out with helium at $1.2 \mathrm{~mL} / \mathrm{min}$ flow rate. The column oven temperature program was: an initial temperature of $50^{\circ} \mathrm{C}$ for $1 \mathrm{~min}$, followed by a $20^{\circ} \mathrm{C} / \mathrm{min}$ rate to $180^{\circ} \mathrm{C}$ and held for $0.5 \mathrm{~min}$, followed then by another ramp of $10^{\circ} \mathrm{C} / \mathrm{min}$ to $240^{\circ} \mathrm{C}$, held for $8 \mathrm{~min}$, and the last ramp of $14^{\circ} \mathrm{C} / \mathrm{min}$ to $300^{\circ} \mathrm{C}$, held for $9.5 \mathrm{~min}$, with a total run time of 32 min. The analytes were monitored by maintaining the $\mu \mathrm{ECD}$ detector at $350^{\circ} \mathrm{C}$.

\section{Sampling and sample collection}

The in vitro experiments were carried out using microplastic free surface water $\mathrm{pH}=6.8$ as analytical matrix. Controlled amounts of microplastics were successive added. This type of water has been chosen to reproduce the adsorption conditions of organochlorine pesticides in microplastics in the aquatic systems where they are found.

Two sets of water samples were prepared introducing $10 \mathrm{~g}$ of PET microplastics in $1000 \mathrm{~mL}$ of surface water and left in contact for 5 days with periodic stirring in room conditions, avoiding the sunlight. The samples were prepared in duplicate.

In the first set of samples, $400 \mathrm{ng}$ of $\mathrm{HCHs}$ isomers $(\alpha, \beta, \gamma, \delta-\mathrm{HCH})$ were added in $1000 \mathrm{~mL}$ surface water while in the second set of samples were added $400 \mathrm{ng}$ OCPs mixture $(\alpha, \beta, \gamma, \delta$ - $\mathrm{HCH}$, heptachlor, heptachlor epoxide, aldrin, dieldrin, endrin, endrin aldehyde, endosulfan I, endosulfan II, endosulfan sulfate, 4,4-DDT, 4,4-DDE, 4,4-DDD).

\section{Sample extraction}

After 5 days the microplastics were filtered through quantitative filter paper from each water sample and a volume of $500 \mathrm{~mL}$ water was extracted with a volume of $20 \mathrm{~mL}$ of hexane. The phases were stirred for 5 minutes and then left to rest for 5 minutes to separate. The organic phase was separated and passed over anhydrous sodium sulfate to retain traces of water, and then was concentrated under a gentle stream of nitrogen to a $1 \mathrm{~mL}$ volume and transferred quantitatively to a 2 $\mathrm{mL} \mathrm{GC}$ vial. After concentration, a volume of $100 \mu \mathrm{L}$ standard $2 \mathrm{mg} / \mathrm{L}$ of PCNB was added as an internal standard. At the same time, an ultrapurified water blank was run through the same steps above. 
Microplastics separated from water were put in contact with $30 \mathrm{~mL}$ hexane, and then sonicated for 60 minutes to extract the adsorbed studied analytes. The organic extract thus obtained was passed over anhydrous sodium sulfate to retain traces of water, evaporated under nitrogen stream to a volume of $1 \mathrm{ml}$. A volume of $100 \mu \mathrm{L}$ of internal standard (PCNB concentration $2 \mathrm{mg} / \mathrm{L}$ ) was added. The concentrated extract was quantitatively transferred to a $2 \mathrm{~mL} \mathrm{GC} \mathrm{vial} \mathrm{and} \mathrm{analyzed}$ by gas chromatography with an ECD detector.

\section{Results and discussions}

a) GC-ECD performance

The GC-ECD method was used to obtain high sensitive results with a good peaks resolution and less interferences.

The calibration curves drawn for all compounds were found to be linear in the range of 2.5 to $200 \mu \mathrm{g} / \mathrm{L}$, with a very good correlation coefficient $\left(\mathrm{R}^{2}>0.99\right.$, Table 2). The instrumental limit of quantification (IQL) which represents the concentration related to signal to noise ratio $(\mathrm{S} / \mathrm{N})$ value of 10 was obtained from the $\mathrm{S} / \mathrm{N}$ of lowest calibration point $(5$ $\mu \mathrm{g} / \mathrm{L})$.

Table 2

PERFORMANCE PARAMETERS FOR METHOD VALIDATION

\begin{tabular}{|l|l|l|l|}
\hline Analyte & $\mathrm{R}_{2}$ & IQL $(\mathrm{ng} / \mathrm{L})^{*}$ & Recovery (\%) \\
\hline$\alpha$-HCH & 0.9994 & 1.43 & 105.5 \\
\hline$\beta$-HCH & 0.9997 & 4.12 & 85.4 \\
\hline$\gamma$-HCH & 0.9991 & 1.58 & 95.8 \\
\hline$\delta$-HCH & 0.9995 & 2.99 & 96.8 \\
\hline Heptachlor & 0.9998 & 1.51 & 110.6 \\
\hline Aldrin & 0.9999 & 1.51 & 105.6 \\
\hline Heptachlor epoxide & 0.9997 & 1.36 & 108.1 \\
\hline Endosulfan I & 0.9999 & 0.61 & 103.6 \\
\hline $4,4-D D E$ & 0.9999 & 0.80 & 96.8 \\
\hline Dieldrin & 0.9999 & 0.58 & 104.4 \\
\hline Endrin & 0.9998 & 0.88 & 81.3 \\
\hline Endosufan II & 0.9997 & 0.64 & 95.1 \\
\hline $4,4-D D D$ & 0.9997 & 0.81 & 95.9 \\
\hline Endrin aldehyde & 0.9983 & 0.77 & 115.2 \\
\hline $4,4-D D T$ & 0.9992 & 1.44 & 102.3 \\
\hline Endosulfan sulfate & 0.9999 & 0.85 & 110.0 \\
\hline
\end{tabular}

*reported at $500 \mathrm{ml}$ water

\section{b) Adsorption HCHs and OCPs class on microplastics and in surface water}

Figure 1 shows the amount of $\alpha, \beta, \gamma, \delta$ - $\mathrm{HCH}$ (ng) isomers and the mix of the chlorinated organic compounds (ng) adsorbed on microplastics.

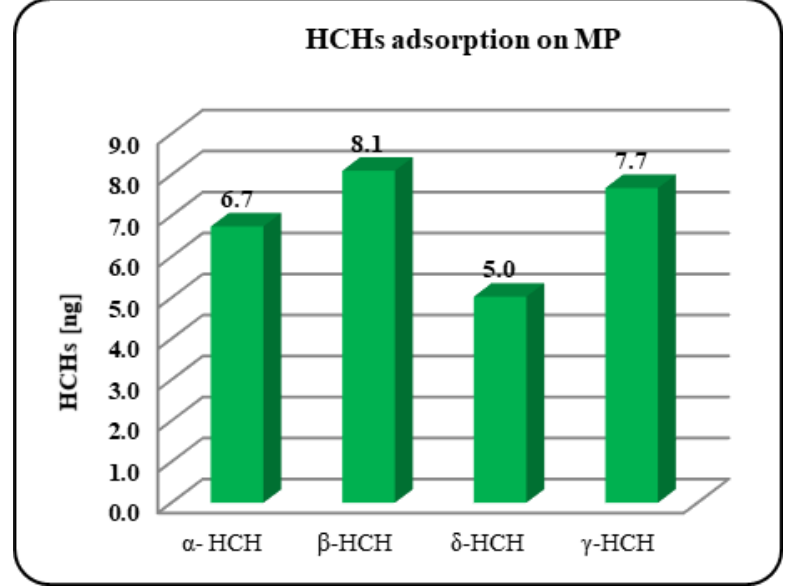

a)

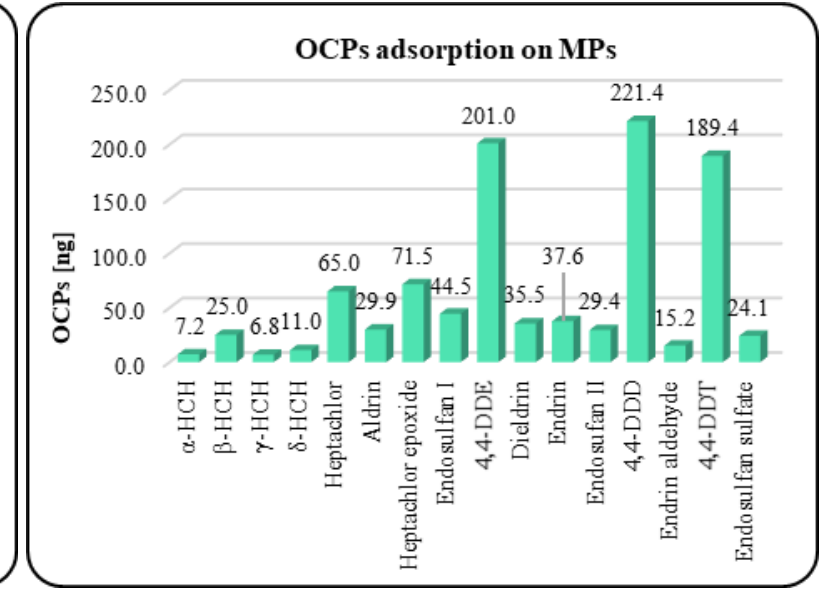

b)

Fig. 1. Chlorinated organic compounds adsorptions in microplastics

[a) HCHs class adsorption on MP; b) OCPs class adsorption on MP]

From the data obtained, it was observed an absolute quantity of $\mathrm{HCHs}$ isomers in the range of 5.0 to $8.1 \mathrm{ng}$ adsorbed on microplastics from $400 \mathrm{ng}$ initially added. The difference between the adsorbed quantities of HCHs isomers was not significant for the first set, but much higher in the second set, even if they have same magnitude order results. It is possible 
that the presence of the other compounds from mix to be responsible for the higher adsorption of HCHs, with 7 to $68 \%$ more than the individual class mix. Above all, $\beta-\mathrm{HCH}$ isomer in the OCPs mixture presented a high sorption (25 ng) compared to the individual HCHs mixture (8.1 ng).

Compared to the individual $\mathrm{HCHs}$ mixture, endrin aldehyde presented also a low adsorption (15.2 ng), while the other compounds adsorbed increase in the order: $\mathrm{HCHs}$ isomers $(\alpha, \beta, \gamma, \delta$ - $\mathrm{HCH})<$ (aldrin, endrin, dieldrin) < (endosulfan I, endosulfan II, endosulfan sulfate) < (heptachlor, heptachlor epoxide) < (4,4-DDE, 4,4-DDD, 4,4-DDT).

The obtained data show a high value of residual OCPs compounds in surface water ranging from $136 \mathrm{ng}$ (DDT) to 422 ng for $\gamma-\mathrm{HCH}$ and a low rate of adsorption of studied OCPs on microplastics. The largest amount of compounds adsorbed on microplastics is represented by: 4,4-DDT (189.4 ng), 4,4-DDD (221.4 ng) and 4,4-DDE (201.0 ng). Because of the hydrophobicity $\left(\log \mathrm{K}_{\mathrm{ow}}=6.36,5.70\right.$, and 5.50, respectively), the highest sorption was obtained for this substance and for his degradation products. Less than $50 \%$ of the amount of OCPs mixture was distributed to the other compounds: heptachlor and heptachlor epoxide with values ranging from $65 \mathrm{ng}$ to $72 \mathrm{ng}$, while aldrin, dieldrin between 35 to $37 \mathrm{ng}$, endosulfan I and endosulfan II between $29 \mathrm{ng}$ to $44 \mathrm{ng}$. HCHs isomers exhibited the smallest adsorption on microplastics ranging from 7 ng to $25 \mathrm{ng}$.

In surface water samples, we observed quantities close to the HCHs isomers in both mixture (HCHs mixture and OCPs mixture).

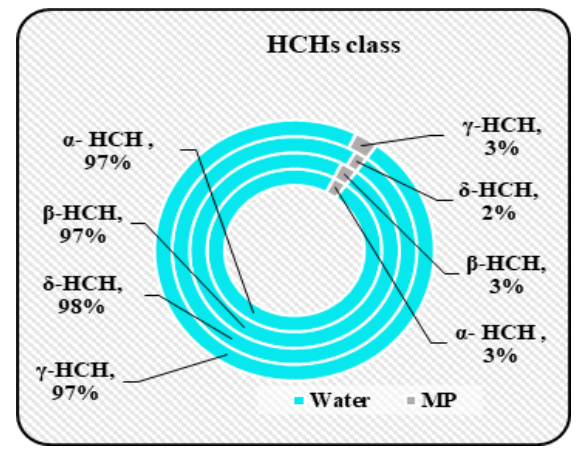

Fig. 2. Percent adsorption of HCHs isomers in surface water and in microplastics

The adsorption rates of HCHs isomers on both microplastics and surface water are shown in Figure 2. The experimental data obtained indicates low percentages (2-3\%) of adsorption of HCHs isomers on microplastics in individual mixture.

Figure 3 shows the percentages of chlorinated organic compounds adsorbed on microplastics and residual surface water.

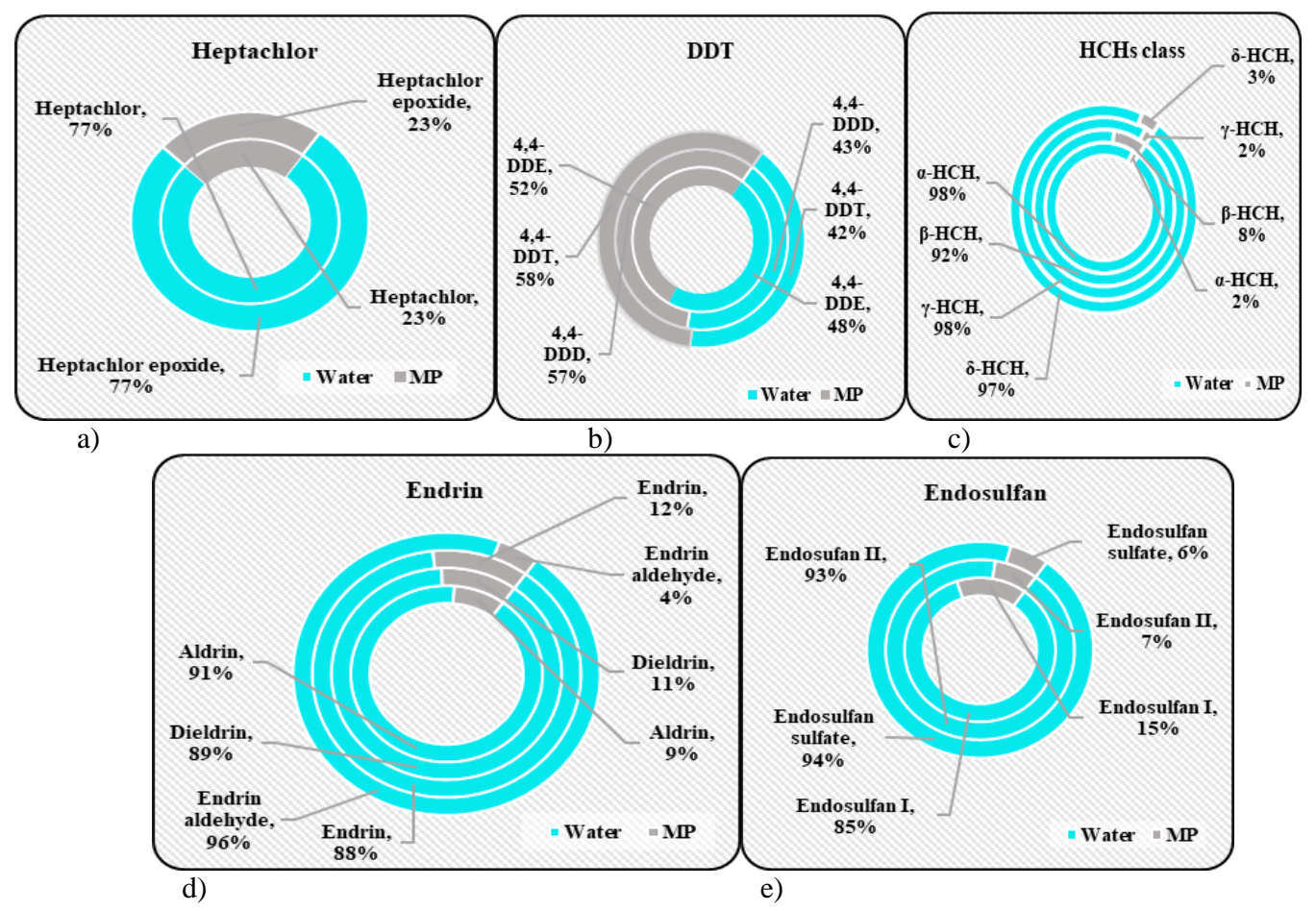

Fig. 3. Adsorption of OCPs recovery in surface water and in microplastics investigated [a) Heptachlor class; b) DDT class; c) HCHs class; d) Endrin class; e) Endosulfan class] 
From the data presented, the highest percentage of organochlorine pesticides adsorbed on microplastics corresponds to the DDT class $(52-58 \%)$, followed by heptachlor (23\%), endosulfan (6-15\%), endrin (4-12\%) and $\mathrm{HCH}$ isomers class (2$8 \%$ ). The data obtained in the present study confirm the literature [20] that DDT, DDD and DDE compounds show the highest degree of adsorption on polyethylene terephthalate (PET) microplastics.

The time of contact period of chlorinated organic pollutants with the microplastics is important in determining the rate of adsorption. Some literature studies [12] establish the adsorption equilibrium of these pollutants studied in less than 72 hours compared with the data from the present study where the contact time was 120 hours and periodic stirring.

\section{Conclusions}

An adsorption processes occurring at the surface of microplastic particles using one of the important class of organic pollutants (organochlorine pesticides) was investigated.

The study shown that these compounds being in contact with the microplastic particles, can be adsorbed on their surfaces and can be transported into natural waters. Contaminated particles may be ingested by aquatic organisms and may bioaccumulate and causing damage to the entire trophic chain.

The study found that the highest percentage of organochlorine pesticides adsorbed on microplastics corresponds to the DDT class $(52-58 \%)$, followed by heptachlor class (23\%), endosulfan class (6-15\%), endrin class (4-12\%) and HCHs isomers class $(2-8 \%), \log \mathrm{K}_{\text {ow }}$ being a useful predictor for plastic sorption rates.

HCHs isomers exhibited the smallest adsorption on microplastics ranging from $7 \mathrm{ng}$ to $25 \mathrm{ng}$ with a low percentage (2$8 \%$ ) in OCPs mixture. $\beta-\mathrm{HCH}$ isomer in the OCPs mixture presented a high sorption (25 ng) compared to the individual HCHs mixture $(8.1 \mathrm{ng})$. The other HCHs isomers $(\alpha, \gamma, \delta)$ show an adsorption of the same order of magnitude in both the HCHs mixture and in mixture with the other chlorinated organic compounds.

Because these pollutants have high persistence, toxicity and bioaccumulative potential, the results of this study on the adsorption of individual contaminants or contaminant mixtures can serve for future research to concerning risk to aquatic ecosystems induced by the plastics presence in surface waters.

Experimental data may vary depending on a number of factors such as: plastic surface area, contaminant exposure time, plastic weathering rates, biofuling, contaminant degradation conditions, contaminant mixes, disintegration rate of polymeric materials and, last but not least, the conditions environmental.

Acknowledgements: This work was realised with the support of the National Research Program Nucleu through contract no 20N/2019, Project code PN 19040101 .

\section{References}

1. MORAR D. A., TEUȘDEA A., TIMAR A., Ingineria Mediului şi Antreprenoriatul Dezvoltării Durabile, 4, no. 1, 2015 , p. 33.

2. PETER R. G., MOORE C. J., VAN FRANEKER J. A., MOLONEY C. L., 364, 2009, p. 1999.

3. ANTHONY A. L., Mar. Poll. Bull., 62, 2011, p. 1596.

4. M. COLE, LINDEQUE P., HALSBAND C., GALLOWAY T. S., Mar. Poll. Bull., 62, 2011, p. 2588.

5. DERRAIK J. G. B., Mar. Poll. Bull., 44, 2002, p. 842.

6. BROWNE M. A., CRUMP P., NIVEN S. J., TEUTEN E., TONKIN A., GALLOWAY T., THOMPSON R., Environ. Sci. Technol. 45, no. 21, 2011, p. 9175.

7. FENDALL S. L., SEWELL M. A., Mar. Poll. Bull., 58, 2009, p. 1225.

8. MORAR D., POPA M., Environ Prot Ecol, 15, no. 3, 2014, p. 916.

9. UNEP, Marine plastic debris and microplastics-Global lessons and research to inspire action and guide policy change. United Nations Environment Programme, Nairobi, 2016, ISBN No: 978-92-807-3580-6

10. United States Environmental Protection Agency, State of the Science White Paper-A Summary of Literature on the Chemical Toxicity of Plastics Pollution to Aquatic Life and Aquatic-Dependent Wildlife, 2016

11. PIRINGER O. G., Rev. Chim. (Bucharest), 59, no. 11, 2008, p. 1186.

12. ALLEN T., FARLEY S., DRAPER J., CLEMENT C., POLIDORO B., J Env Toxicol Stud, 2, no. 1, 2017, p. 1.

13. MATO Y., ISOBE T., TAKADA H., KANEHIRO H., OHTAKE C., KAMINUMA T., Environ. Sci. Technol., 35, 2001 , p. 318.

14. IANCU V., PETRE J., GALAON T., VASILE G. G., RADU G. L., Rev. Chim. (Bucharest), 69, no. 11, 2018 , p. 4148.

15. PETRE J., GALAON T., IANCU V. I., NICULESCU M., International Symposium The Environment and the Industry, 2017, p. 237.

16. CHIRIAC F. L., PAUN I., PIRVU F., IANCU V., GALAON T., Rev. Chim. (Bucharest), 70, no. 6, 2019, p. 2123.

17. TEUTEN E. L., SAQUING J. M., KNAPPE D. R. U., BARLAZ M. A., JONSSON S., ANNIKA B., ROWLAND S. J., THOMPSON R.C., GALLOWAY T. S., YAMASHITA R., OCHI D., WATANUKI Y., MOORE C., VIET P. H., TANA T. S., PRUDENTE M., BOONYATUMANOND R., ZAKARIA M. P., AKKHAVONG K., OGATA Y., HIRAI H., IWASA S., MIZUKAWA K., HAGINO Y., IMAMURA A., SAHA M., TAKADA H., Phil. Trans. R. Soc. B., 364, 2009, p. 2027.

18. PETRE J., GALAON T., IANCU V. I., VASILE G. G., STANESCU E., PASCU F. L., SIMION M., CRUCERU L., Rev. Chim. (Bucharest), 67, no. 8, 2016, p. 1436 .

19. RAZANAJATOVO R. M., DING J., ZHANG S., JIANG H., ZOU H., Mar. Poll. Bull., 136, 2018, p. 516.

20. ROCHA-SANTOS T., DUARTE A., Characterization and Analysis of Microplastics (Comprehensive Analytical Chemistry), 1st Edition, 75, Elsevier, 2017, p. 209. 
21. LI J., ZHANG K., ZHANG H., Environ Pollut, 237, 2018, p. 460.

22. BERGMANN M., GUTOW L., KLAGES M., Marine Anthropogenic Litter, Springer Open, 2015, p. 201.

23. SCHYMANSKI D., GOLDBECKA C., HUMPFB H. U., FÜRST P., Water Research, 129, 2018, p. 154.

24. ENFRIN M., DUMÉE L. F. LEE J., Water Research, 161, 2019, p. 621.

25. LI R., TAN H., ZHANG L., WANG S., WANG Y., YU K., Ecotoxicol Environ Saf, 156, 2018, p. 176.

26. BLAIR R. M., WALDRON S., PHOENIX V., GAUCHOTTE-LINDSAY C., Springer Sci. Rev., 5, 2019, p. 19.

27. *** Secretariat of the Stockholm Convention, http://chm.pops.int

Manuscript received: 31.07 .2019 